J. Lake Sci. (湖泊科学), 2012, 24(2): 294-298

http: //www. jlakes.org. E-mail : jlakes@niglas.ac.cn

(C) 2012 by Journal of Lake Sciences

\title{
太湖浮游生物群体分尺度呼吸率初步研究
}

\author{
钱奎梅 ${ }^{1,2}$, 陈宇炜 ${ }^{2 * *}$ \\ (1:中国矿业大学环境与测绘学院,徐州 221116) \\ (2:中国科学院南京地理与湖泊研究所,南京 210008)
}

摘 要: 浮游生物群体分尺度估测方法在水生生态系统研究中应用越来越普遍,但大型浅水湖泊中不同尺度浮游生物群 体研究鲜见报道. 本文以太湖 2002 年 10 月至 2003 年 9 月的野外实测资料为基础, 系统研究了不同尺度浮游生物群落的 ( $R$ 为浮游生物群体的平均直径, $R \geqslant 41 \mu \mathrm{m}, 2 \mu \mathrm{m} \leqslant R<41 \mu \mathrm{m}, R<2 \mu \mathrm{m}$ ) 呼吸率. 结果表明, 在太湖梅梁湾, $R \geqslant 41 \mu \mathrm{m}$ 的 浮游生物群体 (主要是微囊藻群体) 占优势, 呼吸率占总呼吸率的 $70 \%$ 以上, $R<2 \mu \mathrm{m}$ 的浮游生物 (主要是浮游细菌) 呼 吸率占总呼吸率的 $18 \%$ 左右; 在太湖北部敞水区, $R \geqslant 41 \mu \mathrm{m}$ 的浮游生物的呼吸率占总呼吸率的 $10 \%$ 左右, $R<2 \mu \mathrm{m}$ 的浮 游生物占优势, 其呼吸率能占总呼吸率的 $65 \%$ 以上. 总体来看, 梅梁湾中 $R \geqslant 41 \mu \mathrm{m}$ 的浮游生物群体特别是微囊藻群体呼 吸率占优势, 敞水区微型浮游生物特别是浮游细菌对总呼吸率的贡献很大.

关键词: 太湖;浮游生物;分尺度;呼吸率

\section{Size-fractionated plankton community respiration in Lake Taihu}

\section{QIAN Kuimei ${ }^{1,2} \&$ CHEN Yuwei ${ }^{2}$}

(1: School of Environment Science and Spatial Information, China University of Mining and Technology, Xuzhou 221116, P. R. China)

(2: Nanjing Institute of Geography and Limnology, Chinese Academy of Sciences, Nanjing 210008, P. R. China)

Abstract: Studies on the size fractions of plankton communities in large shallow lakes are rare. Here we report on size fractionated plankton communities from Lake Taihu based on bimonthly measurements in field from October 2002 to September 2003. Based on the diameter $(R)$ of the plankton community we analyzed size fractions of $R \geqslant 41 \mu \mathrm{m}, 2 \mu \mathrm{m} \leqslant R<41 \mu \mathrm{m}$ and $R<2 \mu \mathrm{m}$. The fraction larger than $41 \mu \mathrm{m}$, represented mainly by Microcystis colonies, dominated in Meiliang Bay. The respiration of this fraction contributed over $70 \%$ to the total plankton community respiration, while the fraction $<2 \mu \mathrm{m}$ ( mainly bacteria) contributed about $18 \%$ of the total plankton community respiration. In the center of the lake, the plankton community with $R \geqslant 41 \mu \mathrm{m}$ contributed about $10 \%$ to the total plankton community respiration, while the plankton community $R<2 \mu \mathrm{m}$ contributed about $65 \%$ to the total plankton community respiration. For the whole lake, the plankton community with $R \geqslant 41 \mu \mathrm{m}$, particularly the Microcystis colonies, dominated total plankton community respiration in the northern part of the lake while bacterial respiration was most important in the center of Lake Taihu.

Keywords: Lake Taihu; plankton; size-fractions; respiration

水域生态系统浮游生物的呼吸率和初级生产率是该系统结构、功能及运转状况的重要表征,不同尺度 浮游生物的呼吸率和初级生产率有所不同. 浮游生物群体通过呼吸作用消耗有机碳获得能量, 因此, 呼吸作 用是代谢的中心, 是有机物转化的枢纽, 为其他生命物质的合成提供原料. 在水生生态系统中, 浮游生物主 要包括浮游植物、浮游动物和浮游细菌等. 浮游植物是主要的初级生产者, 为浮游动物等其他生物提供基本 能量;浮游细菌是主要的分解者, 对系统中物质循环和能量流动有重要的贡献. 近 $20 \mathrm{a}$ 来, 尽管用分尺度法

* 国家重点基础研究发展计划“973”项目(2002CB412305)资助. 2011-06-13 收稿;2011-07-22 收修改稿. 钱奎 梅,女, 1982 年生, 博士研究生; E-mail : qiankuimei@ 163.com.

** 通信作者;E-mail:ywchen@ niglas. ac. cn. 
研究不同尺度浮游生物群体已开展较多 ${ }^{[1-5]}$, 但大型浅水湖泊中不同尺度浮游生物群体呼吸率的研究鲜有 报道. 对太湖不同尺度浮游生物的呼吸率进行研究, 可揭示太湖生态系统的功能过程, 合理利用太湖资源. 本研究在太湖长期观测数据的基础上, 通过现场原位实验测定不同尺度下浮游生物群体的呼吸率, 为正确 评价不同尺度浮游生物呼吸率的贡献, 定量研究浅水湖泊浮游生物的群体结构和能量流动过程提供帮助.

\section{1 研究方法}

\section{1 采样地点}

太湖是我国第三大淡水湖泊,水域面积为 $2338 \mathrm{~km}^{2}$, 平均水深 $2.0 \mathrm{~m}^{[6]}$. 由于自然条件和受人为影响程 度不同, 太湖可分为不同湖区, 如梅梁湾、五里湖、贡湖湾、竺山湾等, 其共同的特点是都要接受外来生活和工 业污水, 富营养化程度较严重, 容易发生藻类水华 ${ }^{[7]}$; 另外, 敞水区为开阔水面, 容易受到风浪的影响. 因此, 本 文选择梅梁湾 $\left(31^{\circ} 27^{\prime} 36^{\prime \prime} \mathrm{N}, 120^{\circ} 10^{\prime} 08^{\prime \prime} \mathrm{E}\right)$ 及太湖敞水区 $\left(31^{\circ} 15^{\prime} 10^{\prime \prime} \mathrm{N}, 120^{\circ} 10^{\prime} 07^{\prime \prime} \mathrm{E}\right)$ 具有一定的代表性.

\section{2 生产量和呼吸量测定}

2002 年 10 月至 2003 年 9 月, 通过黑白瓶测溶解氧的方法每月一次测定浮游生物群体的生产量和呼吸 量, 将事先采集的梅梁湾和太湖敞水区水样置于 $250 \mathrm{ml}$ 黑白瓶中, 在太湖湖泊生态系统研究站栈桥平台挂 瓶培养 $4 \mathrm{~h}$, 曝光时段一般是 $10: 00-14: 00$. 溶解氧浓度采用精密的 Winkler 滴定法来测定 ${ }^{[8]}$. 浮游生物群落 呼吸率、每平方米水柱日初级生产量 $(A P)$ 和日呼吸量 $(A R)$ 计算公式为:

浮游生物群落呼吸率 $(R)=($ 原始瓶溶解氧 - 黑瓶溶解氧 $) / 4$

每平方米水柱浮游生物群落日初级生产量 $=($ 黑瓶溶解氧 - 白瓶溶解氧 $) \times 24 / 4$

每平方米水柱浮游生物群落日呼吸量 $=($ 原始瓶溶解氧 - 黑瓶溶解氧 $) \times 24 / 4$

\section{3 分尺度呼吸率的测定}

根据太湖浮游生物个体大小, 一般来说, $R \geqslant 41 \mu \mathrm{m}$ 就是浮游动物和大型浮游植物 $(R$ 为浮游生物群体 的平均直径), $2 \leqslant R<41 \mu \mathrm{m}$ 为大部分浮游植物, $R<2 \mu \mathrm{m}$ 为浮游细菌; 故采用 $41 \mu \mathrm{m}$ 和 $2 \mu \mathrm{m}$ 两个尺度分 界. 本文通过分尺度来初步确定不同门类的情况 (浮游动物、浮游植物和浮游细菌), 没有具体关注附生菌或 者不合尺寸的种类的情况. 将所采水样经 $41 \mu \mathrm{m}$ 和 $2 \mu \mathrm{m}$ 滤膜过滤 (需低度真空, 在 0.7 个大气压下用手洜 完成), 将各粒级同一次过滤获得的滤液分别置于 $250 \mathrm{ml}$ 黑瓶和白瓶中, 在栈桥平台挂瓶培养 $4 \mathrm{~h}$, 曝光时段 为 $10: 00-14: 00$, 不同粒级滤液装瓶时初始溶氧浓度基本一致. 按上述方法计算出 $R \geqslant 41 \mu \mathrm{m} 、 2 \mu \mathrm{m} \leqslant R<$ $41 \mu \mathrm{m}$ 和 $R<2 \mu \mathrm{m}$ 浮游生物群体的呼吸率. 实验期间, 每 2 个月测定一次.

\section{4 数据分析}

数据处理和分析利用 Microsoft Exce1 2003 和 SigmaPlot 8.0 完成,不同处理之间的 ANOVA 分析、回归分 析等多元统计采用 SPSS 17.0 实现.

\section{2 结果}

\section{1 日生产量和日呼吸量}

在梅梁湾和太湖敞水区, $A P$ 和 $A R$ 存在很显著的季节变化 $(P<0.05)$, 秋季的 $A P$ 和 $A R$ 显著高于其它 季节 $(P<0.05)$. 在这两个湖区, $A P$ 和 $A R$ 从 2002 年 11 月到 2003 年 3 月都很低. $A P$ 的最高值 $(8.87 \mathrm{~g}$ $\left.\mathrm{O}_{2} /\left(\mathrm{m}^{2} \cdot \mathrm{d}\right)\right)$ 出现在 2003 年 6 月的梅梁湾, 最低值 $\left(0.34 \mathrm{~g} \mathrm{O}_{2} /\left(\mathrm{m}^{2} \cdot \mathrm{d}\right)\right)$ 出现在 2003 年 3 月的梅梁湾. $A R$ 最高值 $\left(13.35 \mathrm{~g} \mathrm{O}_{2} /\left(\mathrm{m}^{2} \cdot \mathrm{d}\right)\right)$ 出现在 2003 年 6 月的梅梁湾, 最低值 $\left(0.28 \mathrm{~g} \mathrm{O}_{2} /\left(\mathrm{m}^{2} \cdot \mathrm{d}\right)\right)$ 出现在 2003 年 1 月的太湖敞水区.

在梅梁湾和太湖敞水区, $A P$ 和 $A R$ 也存在显著的空间差异 $(P<0.05)$. 梅梁湾 $A P$ 的年平均值为 $3.10 \mathrm{~g} \mathrm{O}_{2} /\left(\mathrm{m}^{2} \cdot \mathrm{d}\right)$, 变化范围为 $0.34 \sim 8.87 \mathrm{~g} \mathrm{O}_{2} /\left(\mathrm{m}^{2} \cdot \mathrm{d}\right)$; 太湖敞水区 $A P$ 的年平均值为 $1.46 \mathrm{~g} \mathrm{O}_{2} /\left(\mathrm{m}^{2} \cdot \mathrm{d}\right)$, 变化范围为 $0.47 \sim 3.04 \mathrm{~g} \mathrm{O}_{2} /\left(\mathrm{m}^{2} \cdot \mathrm{d}\right)$. 梅梁湾 $A R$ 的年平均值为 $4.28 \mathrm{~g} \mathrm{O} /\left(\mathrm{m}^{2} \cdot \mathrm{d}\right)$, 变化范围为 $0.69 \sim$ $13.35 \mathrm{~g} \mathrm{O}_{2} /\left(\mathrm{m}^{2} \cdot \mathrm{d}\right)$, 太湖敞水区 $A R$ 的年平均值为 $2.49 \mathrm{~g} \mathrm{O}_{2} /\left(\mathrm{m}^{2} \cdot \mathrm{d}\right)$, 变化范围为 $0.28 \sim 6.55 \mathrm{~g} \mathrm{O}_{2} /\left(\mathrm{m}^{2} \cdot \mathrm{d}\right)$. 总体来说,梅梁湾的 $A P$ 和 $A R$ 比太湖北部敞水区高 (图 1 ). 

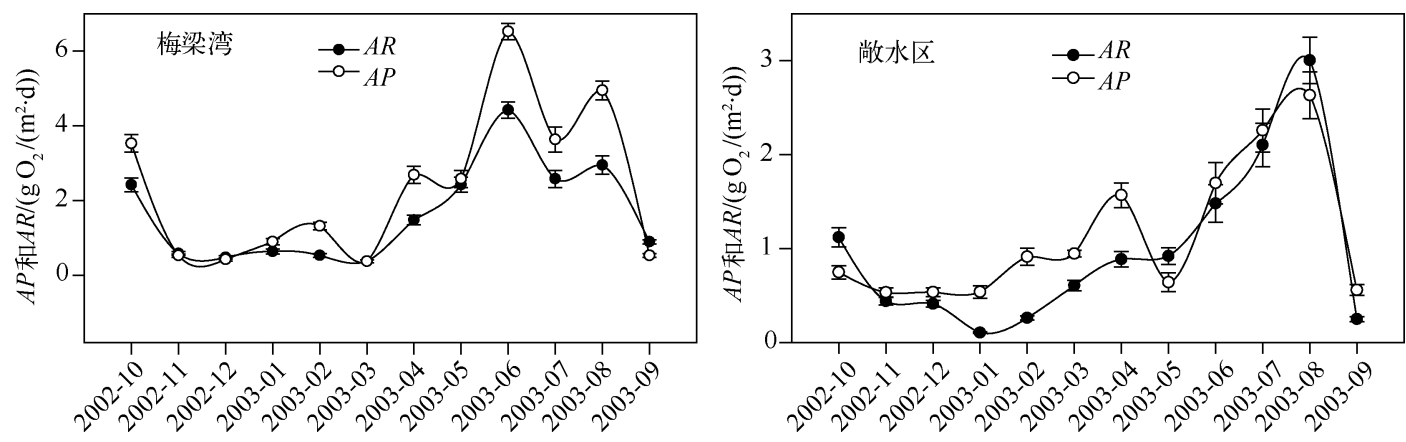

图 1 太湖浮游生物生产量与呼吸量周年变化

Fig. 1 The anniversary changes of plankton's production and respiration in Lake Taihu

\section{2 浮游生物分尺度呼吸率}

不同尺度浮游生物呼吸率有着明显的空间差异 (图 2). 在梅梁湾, $R \geqslant 41 \mu \mathrm{m}$ 的浮游生物呼吸率平均占 总呼吸率的 $51 \% ; 2 \mu \mathrm{m} \leqslant R<41 \mu \mathrm{m}$ 的浮游生物占 $22 \% ; R<2 \mu \mathrm{m}$ 的浮游动物占 $27 \%$. 在敞水区, $R \geqslant 41 \mu \mathrm{m}$ 、 $2 \mu \mathrm{m} \leqslant R<41 \mu \mathrm{m}$ 和 $R<2 \mu \mathrm{m}$ 浮游生物呼吸率平均分别占总呼吸率的 $17 \% 、 6 \%$ 和 $77 \%$.

研究期间太湖不同尺度的浮游生物呼吸率有明显的季节变化 (图 2). 冬季微型浮游生物 $(R<2 \mu \mathrm{m}$ ) 呼吸率占 总呼吸率的比例高, 在 2002 年 10 月份和 2003 年 2 月份分别占 $50 \%$, 但总呼吸率低, 只有 $25 \mathrm{mg} \mathrm{O}_{2} /\left(\mathrm{m}^{3} \cdot \mathrm{h}\right)$; 夏季大型浮游生物 (包括微囊藻群体) 占总呼吸率的比例高, 2003 年 6 月份和 8 月份达到总呼吸率的 $50 \%$ 以 上, 总呼吸率也高, 6 月份达到 $190 \mathrm{mg} \mathrm{O} /\left(\mathrm{m}^{3} \cdot \mathrm{h}\right), 8$ 月份达到 $200 \mathrm{mg} \mathrm{O} /\left(\mathrm{m}^{3} \cdot \mathrm{h}\right)$. 在太湖梅梁湾, $R \geqslant$ $41 \mu \mathrm{m}$ 的浮游生物 (主要是微囊藻) 占优势, 其呼吸率占总呼吸率的 $70 \%$ 以上, $R<2 \mu \mathrm{m}$ 的浮游生物呼吸率 只有总呼吸率的 $18 \%$ 左右; 相对而言, 在太湖北部敞水区, $R \geqslant 41 \mu \mathrm{m}$ 的浮游生物的呼吸率只占总呼吸率的 $10 \%$ 左右, $R<2 \mu \mathrm{m}$ 的浮游生物 (主要是浮游细菌) 占优势, 其呼吸率占总呼吸率的 $65 \%$ 以上(图 3 ). 总体来 看, 太湖微型浮游生物特别是浮游细菌对总呼吸率的贡献很大, 外源有机碳是浮游细菌的重要碳源, 可能对 太湖微型生态食物网的结构功能起着重要作用.
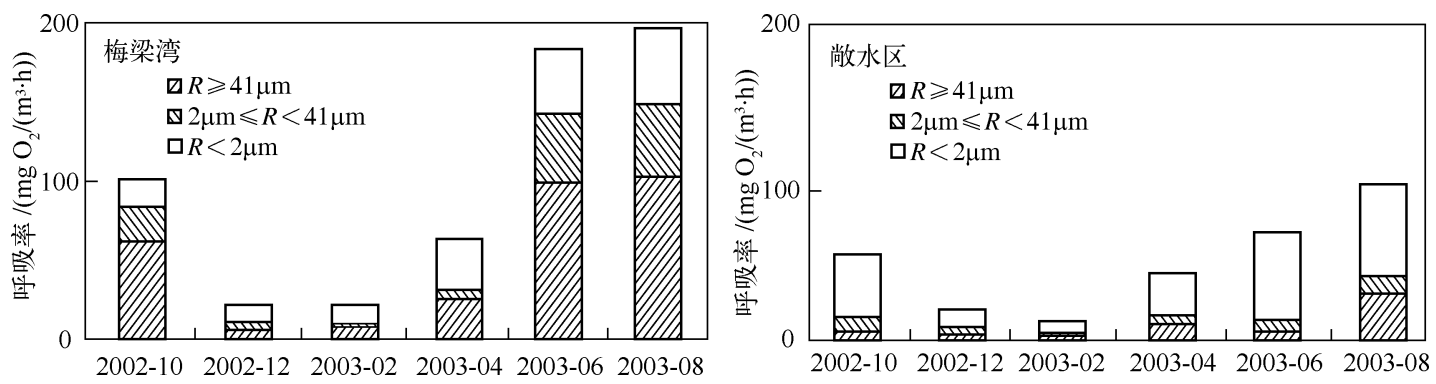

图 2 太湖浮游生物分尺度呼吸率的季节变化

Fig. 2 Seasonal changes of size-fractionated plankton's respiration in Lake Taihu

\section{3 讨论}

\section{1 日生产量和日呼吸量的空间差异和季节变化}

营养盐、光和温度是藻类生长的三大限制因素. 梅梁湾接受无锡市的农业废水、工业废水、生活污水等, 营养盐浓度很高, 因此当其他条件, 如温度、光照等适宜时, 梅梁湾极易出现藻类迅速增殖、水华盈湖的现 象, 因而成为太湖富营养最严重的湖区之一. 而太湖敞水区的营养盐浓度相对较低, 因此, 梅梁湾的日生产 


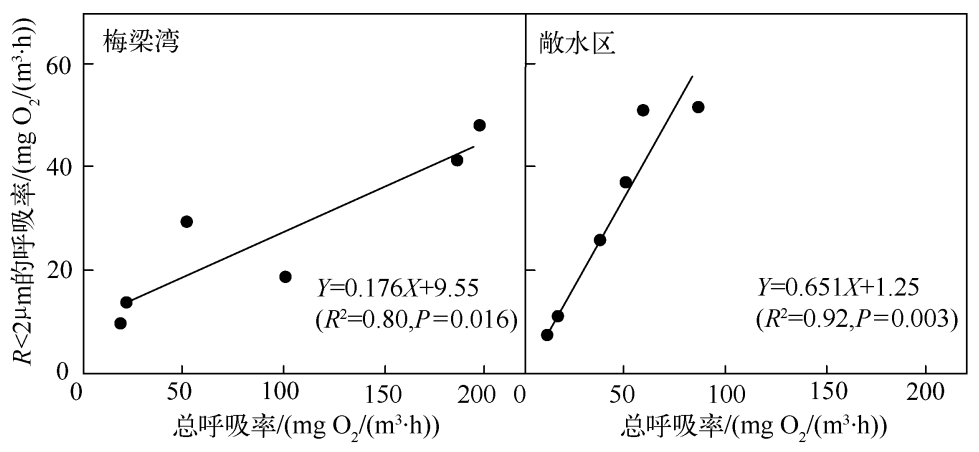

图 3 太湖不同湖区浮游生物呼吸率比例

Fig. 3 Proportions of plankton's respiration rates in different sections of Lake Taihu

量高于太湖敞水区.

温度是影响湖泊生态系统生产者光合和呼吸作用的重要因素之一. 浮游植物的生长受水温影响较大, 随着水温的升高生长加快 ${ }^{[9]}$. 日生产量从 2002 年 11 月到 2003 年 3 月都很低, 这主要是由于冬季温度太低, 浮游植物的生长受到限制. 而从 2002 年 1 月开始日生产量逐渐增加, 可能是由于浮游植物利用冬季积累的 营养盐, 同时随后水温也有所升高的缘故. 而在 2003 年的 7、8 月份, 温度达到了浮游植物生长的最有利条 件, 因此, 浮游植物的日生产量达到最大值. 其中 2003 年 5 月太湖敞水区的生产量较低, 虽然此时温度较高, 但由于这一期间浮游植物被浮游动物摄食较多,因此,浮游植物生物量降低,其生产量相应减少.

\section{2 浮游生物分尺度呼吸率}

在太湖中, $R \geqslant 41 \mu \mathrm{m}$ 为少数大型浮游植物和浮游动物, 包括微囊藻群体; $2 \leqslant R<41 \mu \mathrm{m}$ 为部分浮游植 物; $R<2 \mu \mathrm{m}$ 为浮游细菌. $2 \leqslant R<41 \mu \mathrm{m}$ 的浮游生物呼吸率占总呼吸率的比例最少, 可能是由于在这个粒级 范围内的浮游生物相对较少. 在梅梁湾, $R \geqslant 41 \mu \mathrm{m}$ 浮游生物的呼吸率占总呼吸率的一半, 这是由于梅梁湾 污染严重, 浮游植物特别是微囊藻生长迅速, 其生物量的显著增加使得该区域的呼吸率也相对较高. 在北部 敞水区, $R<2 \mu \mathrm{m}$ 的浮游生物的呼吸率达到了 $77 \%$, 说明了微型浮游生物特别是浮游细菌对总呼吸量的贡 献很大. Valesca 等发现赤道大西洋海岸超过一半的自养初级生产来源于超微型浮游植物 ( < $60 \%$ ), 其所研 究区域是净自养代谢, 呼吸量占总初级生产量的 $51 \%{ }^{[10]}$.

Williams 通过对海洋实验围隔不同粒级浮游生物呼吸进行研究后发现, 小于 $1 \mu \mathrm{m}$ 粒级浮游生物的呼吸 率占浮游生物呼吸率的 $50 \%$, 其原因在于自然海水营养基质贫乏, 细菌个体微小 ${ }^{[11]}, 1 \mu \mathrm{m}$ 滤过液中保留了 绝大多数细菌并极大程度地排除了细菌的主要摄食者一一异养鞭毛虫 ${ }^{[12]}$, 所以, 自然海水 $1 \mu \mathrm{m}$ 滤过液培养 期间 ( $8 \sim 24 \mathrm{~h}$ ), 细菌数量显著增加, 相应的细菌呼吸率也明显增大 ${ }^{[12-13]}$. 太湖敞水区的情况与之类似, 营养 盐浓度相对较低, $R<2 \mu \mathrm{m}$ 浮游生物的呼吸率占浮游生物总呼吸率的 $65 \%$. 而梅梁湾情况与此差别很大, 由 于接受外来污水较多, 营养盐浓度很高, 浮游植物特别是微囊藻群体生长迅速, 生产量高 ${ }^{[14]}$, 相应地, 其呼吸 量总量较高, 同时细菌的呼吸量总量也不低, 但是在总呼吸量的比例中 $R \geqslant 41 \mu \mathrm{m}$ 的浮游生物群体 (主要是 微囊藻群体) 相对较高, 占 $70 \%$ 以上. 在梅梁湾, 总体呼吸量比湖心区高, 是由于梅梁湾的浮游生物生物量远 远高于湖心区. 这是由于梅梁湾营养盐浓度较高, 浮游植物生物量快速增加, 同时使得浮游细菌可利用的有 机碳源较多, 促进了浮游细菌数量的增长 ${ }^{[10]}$, 因此, 梅梁湾总体呼吸量比湖心区高. 在秋季, 梅梁湾的超微型 浮游生物呼吸率比湖心区高, 可能也是因为秋季浮游细菌的生物量相对较高的原因.

太湖浮游生物生物量呈现较明显的周年变化 ${ }^{[14-15]}$, 夏、秋季以微囊藻为绝对优势 (形成蓝藻水华), 温度 升高, 浮游生物的呼吸作用也增强; 冬季没有特别优势的种类, 由于温度很低, 其呼吸作用也受到抑制; 春季 表现为季节的过渡, 分别以几种绿藻和硅藻占优势. 太湖的浮游细菌生物量也有较清楚的周年变化规律. 浮 游细菌数量最小值出现在 3 月份, $3-7$ 月, 细菌的数量呈明显上升趋势, 并且在 7 月份达到最高值, $9-11$ 月, 浮游细菌数量逐渐下降. 浮游细菌数量在湖心区与水温呈显著正相关 $\left(r^{2}=0.4206, n=24, P<0.01\right)$. 太 
湖中浮游细菌数量在不同季节存在显著差异, 夏、秋季节浮游细菌的数量较高, 冬、春季节较低, 受温度的显

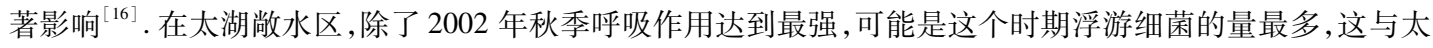
湖秋季蓝藻水华大量死亡有密切关系; 其他季节的细菌生物量的波动相对较小. 太湖梅梁湾中 $7-8$ 月份微 囊藻大量增殖, 其生物量迅速增加, 相应地, 其总呼吸量也迅速增加, 浮游植物增殖速率远远高于浮游细菌 的变化速率, 浮游细菌的变化速率滞后于叶绿素 $\mathrm{a}$ 的变化 ${ }^{[12]}$, 因此, 在 7-8 月梅梁湾中虽然有机物含量比 较丰富, 浮游细菌和原生动物的量也大大增加, 但是以微囊藻为主体的大群体呼吸却占优势.

\section{4 参考文献}

[ 1 ] Hopkinson CS, Sheer JB, Wieburth W. Size fractionated metabolism of coastal plankton. Marine Ecology Progress Series, $1989, \mathbf{5 1}(1 / 2):$ : 155-166.

[2] Butrón A, Iriarte A, Madariaga I. Size-fractionated phytoplankton biomass, primary production and respiration in the Nervión-Ibaizabal estuary: A comparison with other nearshore coastal and estuarine ecosystems from the Bay of Biscay. Continental Shelf Research, 2009, 29(8): 1088-1102.

[ 3 ] Greisberger S, Dokulil MT, Teubner K. A comparison of phytoplankton size-fractions in Mondsee, an alpine lake in Austria: distribution, pigment composition and primary production rates. Aquatic Ecology, 2008, 42 : 379-389.

[ 4 ] 刘国才, 李德尚, 董双林. 对虾养殖生态系不同粒级浮游生物呼吸率和初级生产率测定. 海洋学报, 2001, 23 (6) : 101-107.

[ 5 ] Zhao W, Dong SL. The contribution of size-fractionated plankton to biomass and primary production of phytoplankton in saline-alkaline ponds. Hydrobiologia, 2003, 492: 181-190.

[ 6 ] 黄渏平, 范成新, 兴培民等. 太湖水环境及其污染控制. 北京: 科学出版社, 2001:298.

[ 7 ] Chen YW, Qin BQ, Teubner K et al. Long-term dynamics of phytoplankton assemblages: Microcystis-domination in Lake Taihu, a large shallow lake in China. Plankton Research, 2003, 25: 445-453.

[ 8 ] Wetzel RG, Likens GE. Limnological analyses, 3rd edition. New York: Springer, 2000: 429.

[ 9 ] Smith EM, Kemp WM. Size structure and the production/respiration balance in a coastal plankton community. Limnology and Oceanography, 2001, 46: 473-485.

[10] Valesca PR, Emilio F, Emilio M et al. Latitudinal distribution of microbial plankton abundance, production, and respiration in the Equatorial Atlantic in autumn 2000. Deep-Sea Research I, 2005, 52: 861-880.

[11] Williams PJ. Microbial contribution to overall plankton community respiration studies in enclosures. In: Marine Microcosms, 1980, 305-321.

[12] Hopkinson CS, Sheer JB, Wieburth W. Size fractionated metabolism of coastal plankton. Marine Ecology Progress Series, $1989, \mathbf{5 1}(1 / 2):$ : $155-166$.

[13] Williams PJLeB. Microbial contribution to overall marine plankton metabolism: direct measurement. Oceanologica Acta Paris, 1981, 4(3) : 359-364.

[14] 宋晓兰, 刘正文, 潘宏凯等. 太湖梅梁湾与五里湖浮游植物群落的比较. 湖泊科学, 2007, 19(6): 643-651.

[15] 钱奎梅, 陈宇炜, 宋晓兰. 太湖浮游植物优势种长期演化与富营养化进程的关系. 生态科学, 2008, 27 (2): $65-70$.

[16] 冯 胜, 高 光, 秦伯强等. 太湖北部湖区水体中浮游细菌的动态变化. 湖泊科学, 2006, 18(6): 636-642. 